\title{
Helicobacter, Hygiene, Atopy, and Asthma
}

\author{
Muhammad Miftahussurur ${ }^{1,2,3}$, Iswan A. Nusi ${ }^{3}$, David Y. Graham ${ }^{1}$ and Yoshio Yamaoka ${ }^{1,2 *}$ \\ ${ }^{1}$ Gastroenterology and Hepatology Section, Department of Medicine, Baylor College of Medicine, Houston, TX, United \\ States, ${ }^{2}$ Department of Environmental and Preventive Medicine, Oita University Faculty of Medicine, Yufu, Japan, \\ ${ }^{3}$ Gastroentero-Hepatology Division, Department of Internal Medicine, Faculty of Medicine-Institute of Tropical Disease, \\ Universitas Airlangga, Surabaya, Indonesia
}

\section{OPEN ACCESS}

Edited by:

Mohammad H. Derakhshan,

University of Glasgow,

United Kingdom

Reviewed by:

Zheng Feei Ma,

University of Otago, New Zealand

Andreas L. Lopata,

James Cook University Townsville,

Australia

${ }^{*}$ Correspondence:

Yoshio Yamaoka

yyamaoka@oita-u.ac.jp

Specialty section:

This article was submitted to Microbial Immunology,

a section of the journal

Frontiers in Microbiology

Received: 16 October 2016

Accepted: 23 May 2017

Published: 08 June 2017

Citation:

Miftahussurur M, Nusi IA, Graham DY and Yamaoka Y (2017) Helicobacter,

Hygiene, Atopy, and Asthma.

Front. Microbiol. 8:1034.

doi: 10.3389/fmicb.2017.01034
The hygiene hypothesis links environmental and microbial exposures in early life to the prevalence of atopy, allergy, and asthma. Helicobacter pylori infection is typically acquired in childhood and acquisition of the infection is associated with poor household hygiene. Some population surveys have shown an inverse association between $\mathrm{H}$. pylori infection and atopy, allergy, and asthma leading to the suggestion that $H$. pylori infection may be protective against disease; others consider it simply a biomarker for poor household hygiene. We review the relevant surveys, cohort studies, meta-analyses, and studies testing the protective hypothesis. Overall, the results of surveys and cohort studies are inconsistent, whereas meta-analyses show a significant but weak inverse correlation. In contrast, studies directly testing the protection hypothesis in relation to asthma in populations with poor hygiene and low $\mathrm{H}$. pylori prevalence failed to confirm a protective effect. H. pylori is a major cause of human disease including chronic gastritis, peptic ulcer, and gastric malignancies. H. pylori infections most likely serve as a biomarker for poor hygienic conditions in childhood. We conclude that while synergistic interactions between environmental factors in childhood are important determinants of the pathogenesis of atopy, allergy, and asthma; H. pylori is inversely related to good hygiene and thus it's presence serves as a biomarker rather than for a specific prevention role for $\mathrm{H}$. pylori or H. pylori antigens.

\section{Keywords: Helicobacter pylori, hygiene hypothesis, asthma, atopy, allergy}

\section{INTRODUCTION}

Until recently, the prevalence of asthma (Gershon et al., 2010; de Marco et al., 2012), rhinitis (Hansen et al., 2013), and atopic dermatitis (Duggan et al., 2012) has been increasing in many developed countries. This increase coincided with improved hygiene and socioeconomic conditions and with a decrease in the incidence of many infectious diseases (Bach, 2002) as well as with an increase in the consumption of fossil fuels (Shafiee and Topal, 2009). Although earlier researchers had proposed theories linking atopic disease and hygiene (Blackley, 1873; Leibowitz et al., 1966), in 1989 Strachan proposed a formal theory (i.e., the "hygiene hypothesis") based on studies of the relationship between hay fever and microbial infections in early childhood and adolescence in the United Kingdom (Strachan, 1989). In essence, the hypothesis holds that improved hygiene in early life reduces microbial exposures which were important in priming the immune response and were protective against atopic disorders. This hypothesis was subsequently expanded to cover asthma and autoimmune diseases (Okada et al., 2010). 
Helicobacter pylori is a gram-negative spiral bacterium etiologically associated with both gastric and extragastric diseases including gastric cancer (Graham, 2015). Although the incidence and prevalence of $H$. pylori has markedly decreased in many developed countries, overall at least $50 \%$ of adults worldwide are infected (Leja et al., 2016). The infection is typically acquired in childhood. Because the increase in childhood atopic diseases appeared to correspond to a fall in $H$. pylori acquisition, it was suggested that the two conditions might be related. Several mechanisms were proposed to link the hygiene hypothesis with H. pylori infections (Cremonini and Gasbarrini, 2003; Shiotani et al., 2008). H. pylori infection is thought to influence the process of inducing naïve $\mathrm{T}$ cells in the two main functional groups: T helper 1 (Th1) and helper 2 (Th2) subsets. For example, T cells in the gastric mucosa of $H$. pylori-infected patients produce relatively more interferon $-\gamma$ and relatively less IL- 4 than is found in the gastric mucosa of uninfected individuals suggesting that that H. pylori may lead to a Th1-polarized immune response (Bamford et al., 1998; Sommer et al., 1998). Accordingly, H. pylori infection may also reduce the risk of asthma and allergy due to suppression of the Th2 response (Fox et al., 2000).

T-regulatory (Treg) cells are also increased in H. pyloriinfected human gastric mucosa (Lundgren et al., 2005). Experiments in mice showed that the persistence of $H$. pylori was associated with reprograming of dendritic cell resulting in impairment of T-cells effector function, induction of mucosal T-reg cells and skewing of the immune response toward tolerance (Oertli et al., 2012). Two H. pylori antigens ( $\gamma$-glutamyl transpeptidase and VacA) induced Treg cells in the mouse gastric mucosa resulting in development of tolerance and a reduction in allergic responses (Oertli et al., 2013). Of interest, induction of Treg in the gastric mucosa is also an important step in the establishment and maintenance of $H$. pylori-induced gastric adenocarcinoma (Kandulski et al., 2008, 2010). Although animal studies clearly showed a relation between experimental $H$. pylori infection and protection from ovalbumin-induced asthma (Codolo et al., 2008; Arnold et al., 2011), the neonatal mouse model provides similar results with many different antigens other than those associated with $H$. pylori (Fujimura et al., 2014). Thus, while the results with neonatal mice are reproducible, the marked differences between the immune system of neonatal mice and humans suggest the need for great caution when trying to apply the lessons learned in neonatal mice to human disease (Renz et al., 2012).

Clinical studies in Taiwan have shown that mass eradication of $H$. pylori can remarkedly reduce the incidence of peptic ulcer, gastric cancer and gastric atrophy (Lee Y. C. et al., 2013). H. pylori eradication was also shown to reduce the risk of metachronous cancer after endoscopic treatment of primary gastric cancer (Yoon et al., 2014). While there is current interest in worldwide $H$. pylori eradication to reduce or eliminate gastric cancer (Graham and Uemura, 2006; Graham, 2015; Lee et al., 2016), it has been suggested that an eradication program might have untoward effects if $H$. pylori has a protective role against asthma and atopic diseases (Noverr et al., 2005).

Although most $H$. pylori infections are asymptomatic about $20 \%$ eventuate in a potentially life threatening clinical disease.
The fact that progressive gastric damage is often silent has suggested to some that the bacterium may be harmless, commensal, or even beneficial (Carroll et al., 2004; Mishra, 2013). We collected data from PubMed using keyword combination H. pylori (pylori or Helicobacter) with atopy (atopy or atopic disease or atopic dermatitis), allergy (allergy, allergic disease, allergic rhinitis) and asthma for articles published through March 2016. We excluded abstracts alone or unpublished articles. Here, we summarize the controversies surrounding the role of gastric $H$. pylori colonization as protective against atopy, allergy, and asthma or whether the presence of $H$. pylori is primarily that of a biomarker for poor hygiene.

\section{ASSOCIATION BETWEEN H. PYLORI INFECTION AND ATOPY, ALLERGY, AND ASTHMA}

\section{Positive Studies}

Surveys in Europe, America, and Asia have reported an inverse relationship between $H$. pylori infection and atopy, allergy, and asthma (Kosunen et al., 1997; Chen and Blaser, 2007; Shiotani et al., 2008). Two cross-sectional studies have been based on National Health and Nutrition Examination Surveys in the United States (Chen and Blaser, 2007, 2008) (Table 1). The initial study involved 7,412 adults (NHANES III) and reported that $H$. pylori infection was significantly and inversely associated with dermatitis, rash, and eczema in the last year leading up to the survey (OR 0.73; 95\% CI 0.56-0.96). Similar trends were observed for asthma (OR 0.89; 95\% CI 0.68-1.16) and wheezing (OR 0.73, 95\% CI 0.57-0.94) (Chen and Blaser, 2008). Moreover, $H$. pylori was inversely associated with past (OR 0.69 , 95\% CI $0.45-1.06$ ) or current bouts of asthma (OR $0.41,95 \%$ CI 0.24-0.69), and with recent episodes of wheezing, allergic rhinitis, dermatitis, eczema, and rash (Chen and Blaser, 2008). The other survey of 7,663 adults (NHANES 1999-2000) with asthma, allergic rhinitis, and atopic disorder by the same group (Chen and Blaser, 2007) also revealed that antibody to the $H$. pylori cytotoxin-associated gene product (CagA), a marker of more inflammatory type of $H$. pylori infection, was inversely correlated with asthma (OR 0.79; 95\% CI 0.63-0.99) and allergic rhinitis (OR 0.77; 95\% CI 0.62-0.94), especially among those who developed these conditions in childhood (Table 1; Study No. 10). Moreover, individuals (median age $<43$ years) who tested positive for for CagA and $H$. pylori antibodies were less likely to have developed allergies in the last year leading up to the survey and were less likely to be sensitized to pollens and molds, compared to antibody negative individuals (Chen and Blaser, 2007). Based on these two studies, H. pylori infection was proposed to possibly be protective against asthma and allergy. A subsequent case-control study of 318 adults with asthma and 208 controls in New York (Reibman et al., 2008) also reported the presence of CagA antibody to be significantly and inversely correlated with asthma (OR 0.57, 95\% CI $=0.36-0.89$ ) after adjustment for age, race, and income. In addition, a survey in an adult population in the UK based on urea breath testing for active $H$. pylori infection found a $30 \%$ reduction in the risk of 


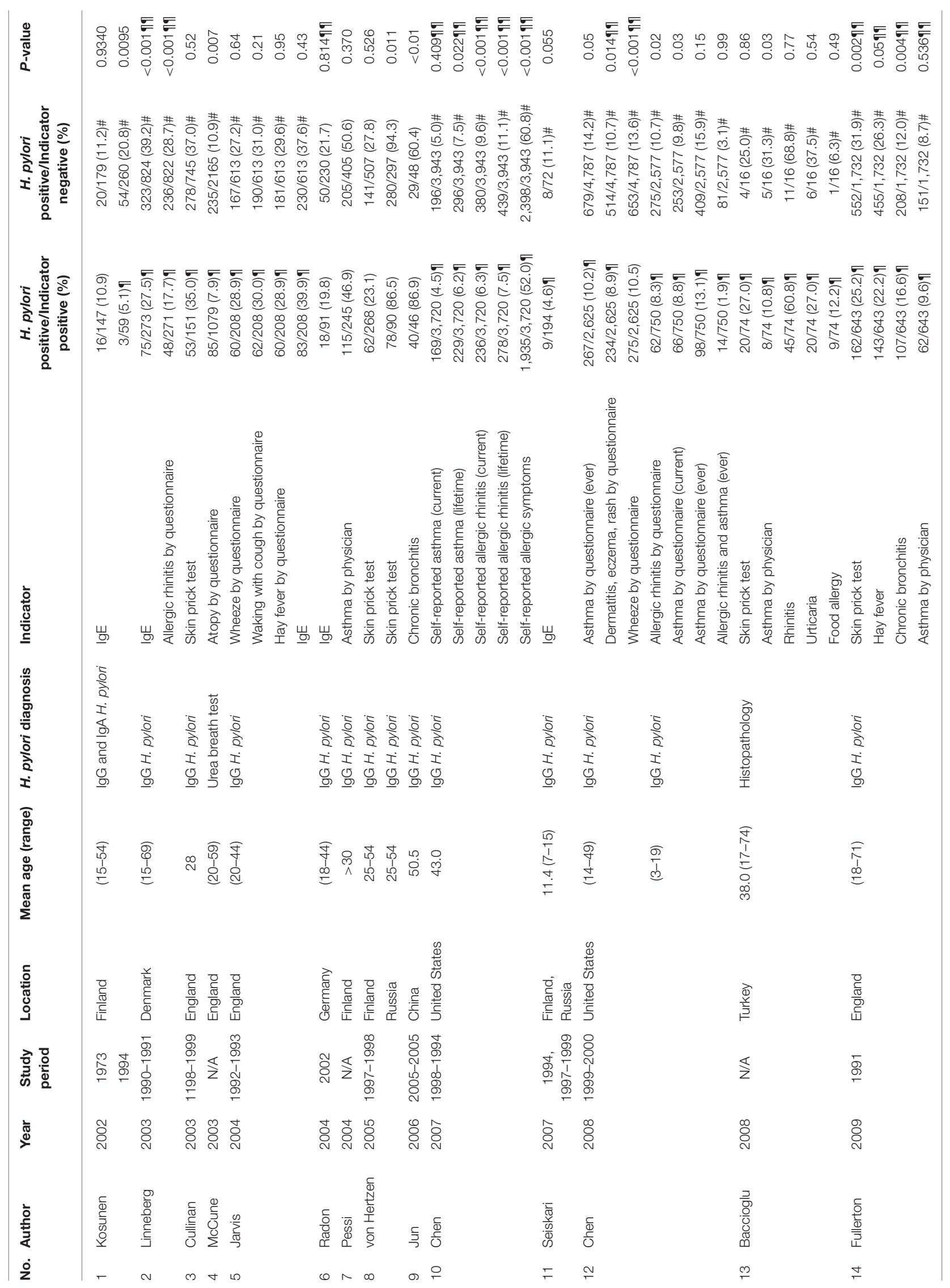




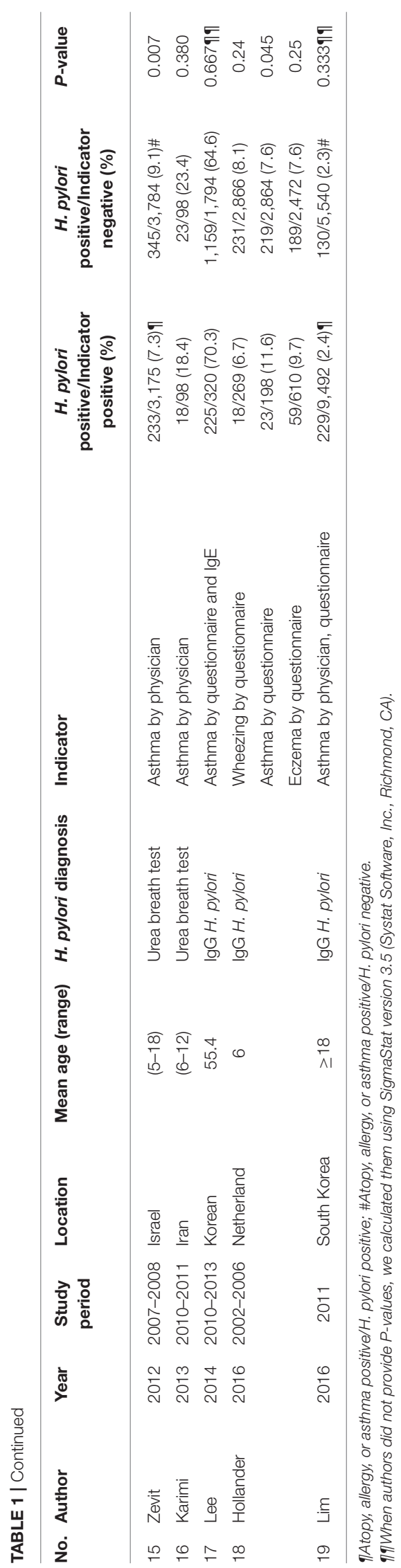

atopy (McCune et al., 2003). Finally, levels of IgE antibodies were found to be higher in adult Finnish individuals who also had $H$. pylori antibodies in 1994 but not in 1973 (Kosunen et al., 2011). Similar results were reported in Danish (Linneberg et al., 2003), Israeli (Zevit et al., 2012), Scandinavian (Janson et al., 2007), and Japanese (Shiotani et al., 2008) populations.

\section{Negative Studies}

Contradictory results include a study in which $H$. pylori failed to protect Finnish siblings equally from atopic sensitivity (53/151, $35 \%$ vs. $278 / 745,37 \%, P=0.52$ ) (Cullinan et al., 2003). Higher IgE antibodies were not associated with $H$. pylori antibodies in Germans (Radon et al., 2004). A survey of 240 atopic patients and 240 controls from a larger cohort of 1,659 Italians (Matricardi et al., 2000) (Table 2) did not find significant associations, although the adjusted OR for atopy decreased along a gradient of exposure to $H$. pylori $(35 / 240,15 \%$ vs. $44 / 240,18 \%, P=$ 0.325). A skin prick test for allergy also failed to discriminate between Turkish volunteers infected with or uninfected with $H$. pylori (Baccioglu et al., 2008), and between those with or without asthma (Annagur et al., 2007). H. pylori antibody prevalence was also higher in Chinese (Tsang et al., 2000) and Japanese (Jun et al., 2005) patients with asthma, but not significantly. In 1,211 subjects randomly selected from 15,000 British adults (Jarvis et al., 2004), the prevalence of cough and hay fever was similar in both infected and uninfected individuals $(62 / 208,30 \%$ vs. $190 / 613,31 \%, P=0.21$ and $60 / 208,28.9 \%$ vs. $181 / 613,29.6 \%$, $P=0.95$, respectively). Wheezing $(P=0.64)$ and allergen-specific serum $\operatorname{IgE}(P=0.43)$ were also higher in $H$. pylori-seropositive adults, but not statistically. Based on this study Jarvis et al. (2004) concluded that the evidence did not link $H$. pylori to cough, hay fever, and wheezing. A survey in China also showed that $H$. pylori and CagA IgG antibodies were more prevalent in patients with chronic bronchitis than in controls (Jun et al., 2006). Finally, a 30-year nested case-control study of 113 participants with adult-onset wheezing and 267 controls in Scotland (Bodner et al., 2000) (Table 2) found that atopic disorders were not significantly associated with $H$. pylori infection. The frequency of wheezing symptoms was comparable between groups, and was weakly but positively correlated with $H$. pylori antibodies. Furthermore, chronic cough and phlegm were more likely to be reported in $H$. pylori seropositive volunteers $(6 / 19,23.1 \%)$ than in seronegative participants $(18 / 150,12 \%, P \leq 0.05)$. The latest studies also showed the contradictory that subjects with past $H$. pylori infection had significantly a highest prevalence of allergy based on IgE status (Lee et al., 2015) and a higher prevalence recent astma in $H$. pylori positive than $H$. pylori negative children (den Hollander et al., 2016).

\section{Cohort Studies}

Three cohort studies have been reported (Cam et al., 2009; Amberbir et al., 2011; Holster et al., 2012) (Table 3). In one study, 74 children in Turkey were followed for 6 years and (Cam et al., 2009) found that atopy was less prevalent, but not significantly, in $H$. pylori-infected children (39.1 vs. $48.1 \%, P$ $=0.215$ ). Similarly, a 3 -year study on a cohort of Ethiopian children revealed that of 832 children infected with $H$. pylori, 235 

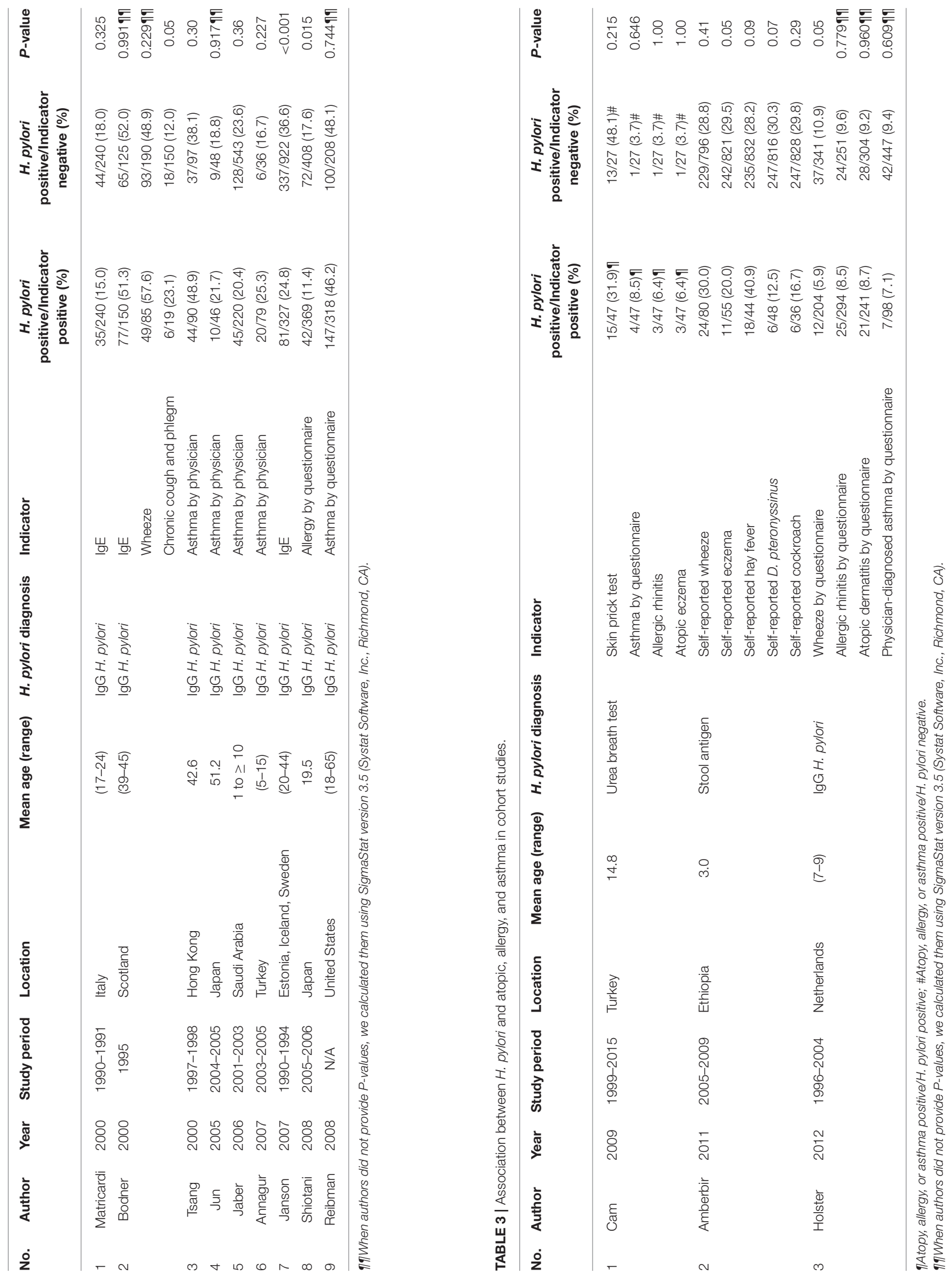
(28.2\%) did not experience hay fever, a prevalence that was not significantly lower than in uninfected children $(18 / 44,40.9 \%, P$ $=0.09$ ). Similar trends were observed for wheezing. Nevertheless, borderline significant protection against eczema was noted (OR $0.49,95 \%$ CI $0.24-1.01, P=0.05)$. H. pylori was inconsistently associated with asthma and allergy in the third study and was not considered either beneficial or protective (Holster et al., 2012).

H. pylori infection is significantly associated with drinking water, toilet type, location of residence, number of residents in a household, and birth order (Malaty et al., 1996; Nurgalieva et al., 2002; Ueda et al., 2003). These associations are welldemonstrated in a cross sectional study with two geographically contiguous cohorts of 266 Finnish and 266 Russian Karelian children living in markedly different cultures, economic systems, and standards of living (e.g., gross domestic product per capita US\$ 32,790 vs. US\$ 3,410) (Seiskari et al., 2007). These children were also surveyed for other microbes associated with poor hygiene, including hepatitis A virus, Toxoplasma gondii, and enterovirus. Importantly, antibodies against all microbes surveyed were higher in Russian Karelian children than in Finnish children. Conversely, allergen-specific IgE was higher in the latter than in the former, but allergy and atopy were not associated with $H$. pylori infection in Finnish children.

\section{Meta-Analyses}

Because cohort studies were inconclusive as to whether $H$. pylori might either be protective or a surrogate for the hygiene hypothesis (Table 3), meta-analyses were performed to increase the statistical power by critically appraising and synthesizing data from multiple studies (Goodman et al., 2015). Meta-analyses are available regarding a possible link between $H$. pylori infection and atopy (Lionetti et al., 2014; Taye et al., 2015) or asthma (Wang et al., 2012, 2013; Zhou et al., 2013). Zhou et al. pooled data from 14 studies (28,283 patients) and found that $H$. pylori infection was significantly less frequent among volunteers with asthma than among controls (OR 0.84; 95\% CI 0.73-0.96, $P=0.013$ ) (Zhou et al., 2013). However, the differences were only significant in North America but not in the Asia and Europe or in a subanalysis related to positivity of CagA. Another meta-analysis noted a significant inverse association between $H$. pylori and asthma in both cross-sectional studies of 30,239 subjects (OR 0.84; 95\% CI $0.74-0.96$ ) and cohort studies of 1,235 subjects (OR 0.82; $95 \%$ CI $0.53-1.27)$. In case-control studies (2,544 subjects) there was a weak inverse association (OR 0.94; 95\% CI 0.79-1.12) (Wang et al., 2013). An 18\% reduction of the risk (OR 0.82; 95\% CI $0.73-0.91, P=0.01$ ) for atopy was also observed among $H$. pyloriinfected participants in a meta-analysis of 21,348 participants that combined various study designs (i.e., mixed analysis of cross sectional and cohort studies) (Taye et al., 2015). Of note, a metaanalysis of five case-control (1,555 participants) studies did not confirm an inverse (OR 1.01, 95\% CI 0.82-1.24) between $H$. pylori and asthma (Wang et al., 2012). A meta-analysis that included asthma within the atopy/allergy cases found that allergy and atopy had a significant inverse association with $H$. pylori in 11 case-control studies of 4,607 participants (OR 0.80, 95\% CI $0.62-0.97)$ whereas only allergy was inversely correlated in the cross-sectional studies of 14,198 participants (OR 0.74, 95\% CI 0.65-1.16) (Lionetti et al., 2014).

These meta-analyses are not without problems as they generally aggregrated multiple heterogeneous conditions into a single group (i.e., different criteria for asthma diagnosis such as physicians vs. symptoms) and, except for few studies, used serological detection of $H$. pylori. Serology does allow one to differentiate between recent and past infections. In addition, the meta-analyses were designed to examine the association between a single agent, $H$. pylori with asthma, allergy and atopy without considering whether it was specifically involved or was acting as a weak surrogate for the hygiene hypothesis.

\section{PROSPECTIVE STUDIES TESTING THE PROTECTION HYPOTHESIS}

Overall, the prevalence of asthma appears to have increased earlier due in part to improvement in diagnostic and awareness. This increase now appears to have peaked and globally the prevalence of asthma has been reported to be decreasing or to have plateued (i.e., in Greece, Turkey, Scotlandia, and England) (Sears, 2014). For example, H. pylori infection has steadily decreased in England (Vyse et al., 2002) and if H. pylori were protective, one would expect the incidence of asthma to increase. However, asthma has decreased in all groups. particularly in children under 5 years (Simpson and Sheikh, 2010). Even more striking is the fact that those children least likely to have $H$. pylori (i.e., the higher socioeconomic class) experienced a greater fall in asthma incidence than seen in the lower socioeconomic classes (in which the prevalence also fell) (Graham, 2015).

The hypothesis that $H$. pylori is protective is based on improved hygiene which reduced $H$. pylori infections leading to increased risk. This hypothesis can be prospectively evaluated by examination of the prevalence of atopic/allergic disease in populations with low $H$. pylori prevalence but low incomes and hygienic standards. Such populations allow one to separate low prevalence of $H$. pylori infection from reduced hygiene and directly attempt to falsify the hypothesis that $H$. pylori provides the protective antigens responsible for protection against disease, in this case asthma.

There are a number of countries where $H$. pylori infections are rare despite poor living conditions (e.g., Malaysia, Indonesia, and Zanzibar) (Farag et al., 2007; Lee Y. Y. et al., 2013; Syam et al., 2015). For example, H. pylori infection is infrequent in Malaysia (Uyub et al., 1994; Sasidharan and Uyub, 2009) and thus one would expect a high rate of any disease against which $H$. pylori offered protection. However, wheezing due to asthma occurs in only $4.3 \%$ of Malaysian children 6-7 years old and and $5.7 \%$ of those $13-14$ years old. Allergic rhinitis in primary school is also rare (5\%) (Quah et al., 2005) and asthma in the general population was noted to be relatively low in comparison to 56 other countries (Raj et al., 2009). In Indonesia (Figure 1), there was no an inverse correlation between the frequency of asthma and $H$. pylori infection: asthma affected $6.9 \%$ in Jakarta $(H$. pylori prevalence $3.2 \%$ ) vs. 


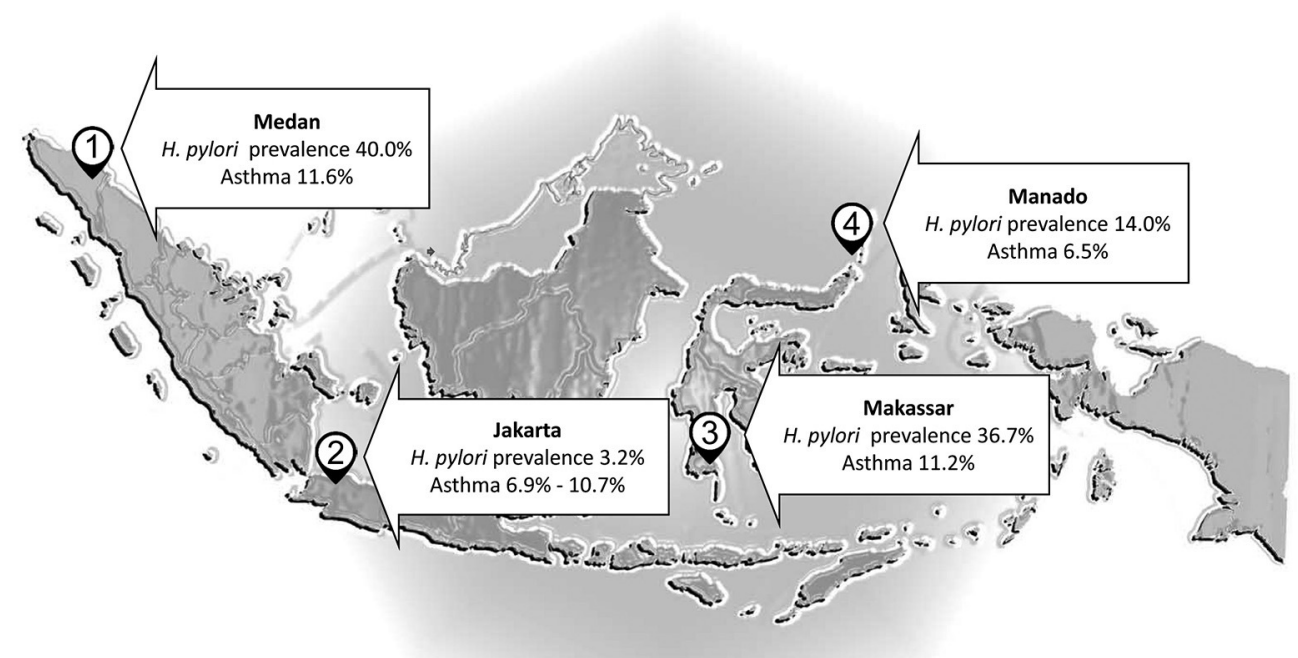

FIGURE 1 | Helicobacter pylori and asthma in Indonesia. The prevalence of asthma is almost similar in Medan, Makassar, and Jakarta although the prevalence $H$. pylori infection is higher in Medan and Makassar than Jakarta.

$6.5 \%$ of the population in Manado ( $H$. pylori prevalence $14 \%$ ) (Sundaru, 2005; Syam et al., 2015). The prevalence of asthma is similar in Medan (11.6\%), Makassar (11.2\%), and Jakarta (10.7\%) although the prevalence $H$. pylori infection is about 12 and 11 times higher in Medan and Makassar than Jakarta, and is about 28 and 23 times higher in Batak and Buginese than Javanese as the predominant ethnics in Medan, Makassar, and Jakarta, respectively (Sundaru, 2005; Syam et al., 2015). Thus, the original projections regarding asthma in countries with low $H$. pylori prevalence and relatively poor hygiene failed.

\section{THE HYGIENE HYPOTHESIS AND H. PYLORI INFECTION}

The hygiene hypothesis suggests that environmental and microbial exposure can shape the developing immune system and confer protection or risk against subsequent immune-mediated disease (von Mutius, 2007). Accordingly, commensal saprophyte microflora or probiotic bacteria with various microbial antigens may have a role in reducing the individual risk of allergy (e.g., living or a farm or having a puppy) (Renz et al., 2012; Campbell et al., 2016). In both Estonia and Sweden, where the prevalence of allergy is widely different (Bjorksten et al., 1999), patients with allergy harbored less lactobacilli and bifidobacterium than controls, regardless of exposure to antibiotics. Of note, Estonian children with allergy harbored a higher number of aerobic microorganisms, especially coliforms, than Staphylococcus aureus, which was dominant in allergic Swedish children. However, another study reported that lactic acid bacteria and bifidobacterium were comparable between wheezing patients sensitized or not sensitized in childhood (Murray et al., 2005).

Sheikh and Strachan (Sheikh and Strachan, 2004) clarified that the hygiene hypothesis is "framed in conceptual rather than specific terms." Therefore, the protective effects of poor hygiene is likely due to synergism of multiple factors in the host and environment, rather than to a single agent (Vercelli, 2006). For example, adolescents who grow up on farms are less prone to asthma and allergic rhinitis than those who do not, possibly related to consumption of farm milk with higher concentrations of gram-negative bacteria and lipopolysaccharides (Riedler et al., 2001; Campbell et al., 2016). A recent meta-analysis across 14 countries (10,201 participants) also confirmed the role of the farm environment as a protective allergic risk and marker of microbial diversity for the inner city population (Campbell et al., 2016). Farms abound in microbial products, molds, and fungi and daily contact with these drive the maturation of immunity and reduce the risk of atopy and asthma (von Mutius, 2007). The prevention approach which was proposed as primary and secondary prevention of allergic diseases also emphasized not only a single agent, but multifactorial (i.e., hypoallergenic formula and reducing several allergens exposure) (Halken, 2004). Finally, it is also possible that protective events occur prior to childhood. For example, repeated pregnancy or intrauterine environment are associated with atopy (von Mutius, 2007).

Overall, allergy and asthma are considered multifactorial diseases triggered by interactions between the environment and host genes (McLeish and Turner, 2007). In general, allergic disorders are more prevalent in the northern than in the 
southern hemisphere, particularly in developed countries, in which rapid environmental changes in the last decades has led to increased outdoor and indoor pollution, climate change, and improved hygiene (Lionetti et al., 2014). Nonetheless, the hygiene hypothesis is not universally applicable, such as in the community with the lowest per capita income in New York. In this community, Afro-American and Hispanic-American children live in households with poor standards of living and hygiene, but exposure to various allergens and viruses paradoxically trigger asthma hospitalizations, with mortality rates more than five times higher than the national average (Webber et al., 2002; Garn and Renz, 2007).

\section{IS $\boldsymbol{H}$. PYLORI INFECTION BENEFICIAL?}

The ancestor of $H$. pylori is believed to have established an ecological niche in the human stomach at least 100,000 years ago and then co-evolved with the host (Covacci et al., 1999). Nevertheless, its long history in the human stomach provides no information regarding whether $H$. pylori infection might be beneficial (Carroll et al., 2004; Mishra, 2013). For instance, hepatitis B virus is not considered commensal nor potentially beneficial, even though it accompanied humans from Africa 100,000-150,000 years ago (Robertson and Margolis, 2002). Hepatitis B infects one third of the global population, of whom more than 350 million are chronically infected. Like $H$. pylori the majority remain asymptomatic while the disease progresses with a small proportion presenting with complicated cirrhosis or hepatocellular carcinoma (El-Serag, 2012). Similarly, Mycobacterium tuberculosis continues to be a target of eradication even today, particularly in developing countries, even though it accompanied humans out of Africa, and caused deaths in one of five adults in Europe and North America between the 17 and 19th centuries (Comas et al., 2013). H. pylori is a primary cause peptic ulcers and gastric cancer (IARC, 1994).

\section{REFERENCES}

Amberbir, A., Medhin, G., Erku, W., Alem, A., Simms, R., Robinson, K., et al. (2011). Effects of Helicobacter pylori, geohelminth infection and selected commensal bacteria on the risk of allergic disease and sensitization in 3-year-old Ethiopian children. Clin. Exp. Allergy 41, 1422-1430. doi: 10.1111/j.1365-2222.2011.03831.x

Annagur, A., Kendirli, S. G., Yilmaz, M., Altintas, D. U., and Inal, A. (2007). Is there any relationship between asthma and asthma attack in children and atypical bacterial infections; Chlamydia pneumoniae, Mycoplasma pneumoniae and Helicobacter pylori. J. Trop. Pediatr. 53, 313-318. doi: 10.1093/tropej/ fmm040

Arnold, I. C., Dehzad, N., Reuter, S., Martin, H., Becher, B., Taube, C., et al. (2011). Helicobacter pylori infection prevents allergic asthma in mouse models through the induction of regulatory T cells. J. Clin. Invest. 121, 3088-3093. doi: 10.1172/JCI45041

Baccioglu, A., Kalpaklioglu, F., Guliter, S., and Yakaryilmaz, F. (2008). Helicobacter pylori in allergic inflammation-fact or fiction? Allergol. Immunopathol. 36, 85-89. doi: $10.1157 / 13120393$

Bach, J. F. (2002). The effect of infections on susceptibility to autoimmune and allergic diseases. N. Engl. J. Med. 347, 911-920. doi: 10.1056/NEJMra020100

\section{SUMMARY}

H. pylori infection most likely acts as a weak surrogate for the presence of poor hygiene. The hypothesis that $H$. pylori or specific $H$. pylori antigens provide protective antigens reducing the frequence of atopy, allergy, or asthma is not supported by the current data and was falsified in experiments testing projections of the hypothesis. We conclude that $H$. pylori is a major human pathogen that causes progressive damage to the stomach. The infection is etiologically associated with chronic gastritis, peptic ulcer, and gastric malignancies, and should be eradicated.

\section{AUTHOR CONTRIBUTIONS}

MM, IN, DG, and YY contributed to data collection, analysis, and interpretation, and wrote the manuscript. YY and DG revised the manuscript to include important content. All authors read and approved the final version of the manuscript.

\section{FUNDING}

YY is supported in part by grants from the National Institutes of Health (DK62813) and by Grants-in-Aid for Scientific Research from the Ministry of Education, Culture, Sports, Science, and Technology of Japan $(25293104,26640114,15 \mathrm{H} 02657$, and $16 \mathrm{H} 05191)$. YY and MM are also supported by the Institutional Program for Young Researcher Overseas Visits of the Japan Society for the Promotion of Science, and by the Strategic Funds for the Promotion of Science and Technology from Japan Science and Technology Agency. DG is supported in part by the Office of Research and Development Medical Research Service Department of Veterans Affairs, Public Health Service grants R01 DK062813 and DK56338 which funds the Texas Medical Center Digestive Diseases Center. The contents are solely the responsibility of the authors and do not necessarily represent the official views of the VA or NIH.

Bamford, K. B., Fan, X., Crowe, S. E., Leary, J. F., Gourley, W. K., Luthra, G. K., et al. (1998). Lymphocytes in the human gastric mucosa during Helicobacter pylori have a T helper cell 1 phenotype. Gastroenterology 114, 482-492. doi: 10.1016/S0016-5085(98)70531-1

Bjorksten, B., Naaber, P., Sepp, E., and Mikelsaar, M. (1999). The intestinal microflora in allergic Estonian and Swedish 2-year-old children. Clin. Exp. Allergy 29, 342-346.

Blackley, C. H. (1873). Experimental Researches on the Causes and Nature of Catarrhus Aestivus (Hay-Fever and Hay-Asthma). London: Baillière Tindall and Cox.

Bodner, C., Anderson, W. J., Reid, T. S., and Godden, D. J. (2000). Childhood exposure to infection and risk of adult onset wheeze and atopy. Thorax 55, 383-387. doi: 10.1136/thorax.55.5.383

Cam, S., Ertem, D., Bahceciler, N., Akkoc, T., Barlan, I., and Pehlivanoglu, E. (2009). The interaction between Helicobacter pylori and atopy: does inverse association really exist? Helicobacter 14, 1-8. doi: 10.1111/j.1523-5378.2009.00660.x

Campbell, B., Raherison, C., Lodge, C. J., Lowe, A. J., Gislason, T., Heinrich, J., et al. (2016). The effects of growing up on a farm on adult lung function and allergic phenotypes: an international population-based study. Thorax 72 , 236-244. doi: 10.1136/thoraxjnl-2015-208154 
Carroll, I. M., Khan, A. A., and Ahmed, N. (2004). Revisiting the pestilence of Helicobacter pylori: insights into geographical genomics and pathogen evolution. Infect. Genet. Evol. 4, 81-90. doi: 10.1016/j.meegid.2004.01.006

Chen, Y., and Blaser, M. J. (2007). Inverse associations of Helicobacter pylori with asthma and allergy. Arch. Int. Med. 167, 821-827. doi: $10.1001 /$ archinte.167.8.821

Chen, Y., and Blaser, M. J. (2008). Helicobacter pylori colonization is inversely associated with childhood asthma. J. Infect. Dis. 198, 553-560. doi: 10.1086/590158

Codolo, G., Mazzi, P., Amedei, A., Del Prete, G., Berton, G., D’Elios, M. M., et al. (2008). The neutrophil-activating protein of Helicobacter pylori downmodulates Th2 inflammation in ovalbumin-induced allergic asthma. Cell. Microbiol. 10, 2355-2363. doi: 10.1111/j.1462-5822.2008.01217.x

Comas, I., Coscolla, M., Luo, T., Borrell, S., Holt, K. E., Kato-Maeda, M., et al. (2013). Out-of-Africa migration and Neolithic coexpansion of Mycobacterium tuberculosis with modern humans. Nat. Genet. 45, 1176-1182. doi: 10.1038/ng.2744

Covacci, A., Telford, J. L., Del Giudice, G., Parsonnet, J., and Rappuoli, R. (1999). Helicobacter pylori virulence and genetic geography. Science 284, 1328-1333. doi: 10.1126/science.284.5418.1328

Cremonini, F., and Gasbarrini, A. (2003). Atopy, Helicobacter pylori and the hygiene hypothesis. Eur. J. Gastroenterol. Hepatol. 15, 635-636. doi: 10.1097/00042737-200306000-00009

Cullinan, P., Harris, J. M., Newman Taylor, A. J., Jones, M., Taylor, P., Dave, J. R., et al. (2003). Can early infection explain the sibling effect in adult atopy? Eur. Respir. J. 22, 956-961. doi: 10.1183/09031936.03.00039102

de Marco, R., Cappa, V., Accordini, S., Rava, M., Antonicelli, L., Bortolami, O., et al. (2012). Trends in the prevalence of asthma and allergic rhinitis in Italy between 1991 and 2010. Eur. Respir. J. 39, 883-892. doi: 10.1183/09031936.00061611

den Hollander, W. J., Sonnenschein-van der Voort, A. M., Holster, I. L., de Jongste, J. C., Jaddoe, V. W., Hofman, A., et al. (2016). Helicobacter pylori in children with asthmatic conditions at school age, and their mothers. Aliment. Pharmacol. Ther. 43, 933-943. doi: 10.1111/apt.13572

Duggan, E. M., Sturley, J., Fitzgerald, A. P., Perry, I. J., and Hourihane, J. O. (2012). The 2002-2007 trends of prevalence of asthma, allergic rhinitis and eczema in Irish schoolchildren. Pediatr. Allergy Immunol. 23, 464-471. doi: 10.1111/j.1399-3038.2012.01291.x

El-Serag, H. B. (2012). Epidemiology of viral hepatitis and hepatocellular carcinoma. Gastroenterology 142, 1264.e1-1273.e1. doi: 10.1053/j.gastro.2011.12.061

Farag, T. H., Stoltzfus, R. J., Khalfan, S. S., and Tielsch, J. M. (2007). Unexpectedly low prevalence of Helicobacter pylori infection among pregnant women on Pemba Island, Zanzibar. Trans. R. Soc. Trop. Med. Hyg. 101, 915-922. doi: 10.1016/j.trstmh.2007.05.003

Fox, J. G., Beck, P., Dangler, C. A., Whary, M. T., Wang, T. C., Shi, H. N., et al. (2000). Concurrent enteric helminth infection modulates inflammation and gastric immune responses and reduces helicobacter-induced gastric atrophy. Nat. Med. 6, 536-542. doi: 10.1038/75015

Fujimura, K. E., Demoor, T., Rauch, M., Faruqi, A. A., Jang, S., Johnson, C. C., et al. (2014). House dust exposure mediates gut microbiome Lactobacillus enrichment and airway immune defense against allergens and virus infection. Proc. Nat. Acad. Sci. U.S.A. 111, 805-810. doi: 10.1073/pnas.1310750111

Garn, H., and Renz, H. (2007). Epidemiological and immunological evidence for the hygiene hypothesis. Immunobiology 212, 441-452. doi: 10.1016/j.imbio.2007.03.006

Gershon, A. S., Guan, J., Wang, C., and To, T. (2010). Trends in asthma prevalence and incidence in Ontario, Canada, 1996-2005: a population study. Am. J. Epidemiol. 172, 728-736. doi: 10.1093/aje/kwq189

Goodman, J. E., Petito Boyce, C., Sax, S. N., Beyer, L. A., and Prueitt, R. L. (2015). Rethinking meta-analysis: applications for air pollution data and beyond. Risk Anal. 35, 1017-1039. doi: 10.1111/risa.12405

Graham, D. Y. (2015). Helicobacter pylori update: gastric cancer, reliable therapy, and possible benefits. Gastroenterology 148, 719.e3-731.e3. doi: 10.1053/j.gastro.2015.01.040

Graham, D. Y., and Uemura, N. (2006). Natural history of gastric cancer after Helicobacter pylori eradication in Japan: after endoscopic resection, after treatment of the general population, and naturally. Helicobacter 11, 139-143. doi: 10.1111/j.1523-5378.2006.00391.x
Halken, S. (2004). Prevention of allergic disease in childhood: clinical and epidemiological aspects of primary and secondary allergy prevention. Pediatr. Allergy Immunol. 15(Suppl. 16), 4-5, 9-32. doi: 10.1111/j.1399-3038.2004.0148b.x

Hansen, T. E., Evjenth, B., and Holt, J. (2013). Increasing prevalence of asthma, allergic rhinoconjunctivitis and eczema among schoolchildren: three surveys during the period 1985-2008. Acta Paediatr. 102, 47-52. doi: 10.1111/apa. 12030

Holster, I. L., Vila, A. M., Caudri, D., den Hoed, C. M., Perez-Perez, G. I., Blaser, M. J., et al. (2012). The impact of Helicobacter pylori on atopic disorders in childhood. Helicobacter 17, 232-237. doi: 10.1111/j.1523-5378.2012.00934.x

IARC (1994). Monographs on the Evaluation of Carcinogenic Risks to Humans, Schistosomes, Liver flukes and Helicobacter pylori. International Agency for Research on Cancer, Lyon.

Janson, C., Asbjornsdottir, H., Birgisdottir, A., Sigurjonsdottir, R. B., Gunnbjornsdottir, M., Gislason, D., et al. (2007). The effect of infectious burden on the prevalence of atopy and respiratory allergies in Iceland, Estonia, and Sweden. J. Allergy Clin. Immunol. 120, 673-679. doi: 10.1016/j.jaci.2007.05.003

Jarvis, D., Luczynska, C., Chinn, S., and Burney, P. (2004). The association of hepatitis A and Helicobacter pylori with sensitization to common allergens, asthma and hay fever in a population of young British adults. Allergy 59, 1063-1067. doi: 10.1111/j.1398-9995.2004.00539.x

Jun, Z. J., Lei, Y., Shimizu, Y., Dobashi, K., and Mori, M. (2005). Helicobacter pylori seroprevalence in patients with mild asthma. Tohoku J. Exp. Med. 207, 287-291. doi: $10.1620 /$ tjem.207.287

Jun, Z. J., Lei, Y., Shimizu, Y., Dobashi, K., and Mori, M. (2006). High seroprevalence of Helicobacter pylori in chronic bronchitis among Chinese population. Tohoku J. Exp. Med. 208, 327-331. doi: 10.1620/tjem. 208.327

Kandulski, A., Malfertheiner, P., and Wex, T. (2010). Role of regulatory T-cells in H. pylori-induced gastritis and gastric cancer. Anticancer Res. 30, 1093-1103.

Kandulski, A., Wex, T., Kuester, D., Peitz, U., Gebert, I., Roessner, A., et al. (2008). Naturally occurring regulatory $\mathrm{T}$ cells $\left(\mathrm{CD} 4^{+}, \mathrm{CD} 25^{\text {high }}\right.$, $\mathrm{FOXP}^{+}$) in the antrum and cardia are associated with higher $\mathrm{H}$. pylori colonization and increased gene expression of TGF- $\beta 1$. Helicobacter 13, 295-303. doi: 10.1111/j.1523-5378.2008.00612.x

Kosunen, T. U., Aromaa, A., Knekt, P., Salomaa, A., Rautelin, H., Lohi, P., et al. (1997). Helicobacter antibodies in 1973 and 1994 in the adult population of Vammala, Finland. Epidemiol. Infect. 119, 29-34. doi: $10.1017 /$ S0950268897007565

Kosunen, T. U., Pukkala, E., Sarna, S., Seppala, K., Aromaa, A., Knekt, P., et al. (2011). Gastric cancers in Finnish patients after cure of Helicobacter pylori infection: a cohort study. Int. J. Cancer 128, 433-439. doi: 10.1002/ijc.25337

Lee, S. P., Lee, S. Y., Kim, J. H., Sung, I. K., Park, H. S., Shim, C. S., et al. (2015). Correlation between Helicobacter pylori infection, IgE hypersensitivity, and allergic disease in Korean adults. Helicobacter 20, 49-55. doi: 10.1111/hel.12173

Lee, Y. C., Chen, T. H., Chiu, H. M., Shun, C. T., Chiang, H., Liu, T. Y., et al. (2013). The benefit of mass eradication of Helicobacter pylori infection: a community-based study of gastric cancer prevention. Gut 62, 676-682. doi: 10.1136/gutjnl-2012-302240

Lee, Y. C., Chiang, T. H., Chou, C. K., Tu, Y. K., Liao, W. C., Wu, M. S., et al. (2016). Association between Helicobacter pylori eradication and gastric cancer incidence: a systematic review and meta-analysis. Gastroenterology 150, 1113.e5-1124.e5. doi: 10.1053/j.gastro.2016.01.028

Lee, Y. Y., Mahendra Raj, S., and Graham, D. Y. (2013). Helicobacter pylori infection-a boon or a bane: lessons from studies in a low-prevalence population. Helicobacter 18, 338-346. doi: 10.1111/hel.12058

Leibowitz, U., Antonovsky, A., Medalie, J. M., Smith, H. A., Halpern, L., and Alter, M. (1966). Epidemiological study of multiple sclerosis in Israel. II. Multiple sclerosis and level of sanitation. J. Neurol. Neurosurg. Psychiatry 29, 60-68. doi: 10.1136/jnnp.29.1.60

Leja, M., Axon, A., and Brenner, H. (2016). Epidemiology of Helicobacter pylori infection. Helicobacter 21(Suppl. 1), 3-7. doi: 10.1111/hel. 12332

Linneberg, A., Ostergaard, C., Tvede, M., Andersen, L. P., Nielsen, N. H., Madsen, F., et al. (2003). IgG antibodies against microorganisms and atopic disease in Danish adults: the Copenhagen Allergy Study. J. Allergy Clin. Immunol. 111, 847-853. doi: 10.1067/mai.2003.1335 
Lionetti, E., Leonardi, S., Lanzafame, A., Garozzo, M. T., Filippelli, M., Tomarchio, S., et al. (2014). Helicobacter pylori infection and atopic diseases: is there a relationship? A systematic review and meta-analysis. World J. Gastroenterol. 20, 17635-17647. doi: 10.3748/wjg.v20.i46.17635

Lundgren, A., Stromberg, E., Sjoling, A., Lindholm, C., Enarsson, K., Edebo, A., et al. (2005). Mucosal FOXP3-expressing $\mathrm{CD}^{+} \mathrm{CD} 25$ high regulatory $\mathrm{T}$ cells in Helicobacter pylori-infected patients. Infect. Immun. 73, 523-531. doi: 10.1128/IAI.73.1.523-531.2005

Malaty, H. M., Paykov, V., Bykova, O., Ross, A., Graham, D. P., Anneger, J. F., et al. (1996). Helicobacter pylori and socioeconomic factors in Russia. Helicobacter 1 , 82-87. doi: 10.1111/j.1523-5378.1996.tb00015.x

Matricardi, P. M., Rosmini, F., Riondino, S., Fortini, M., Ferrigno, L., Rapicetta, M., et al. (2000). Exposure to foodborne and orofecal microbes versus airborne viruses in relation to atopy and allergic asthma: epidemiological study. $B M J$ 320, 412-417. doi: 10.1136/bmj.320.7232.412

McCune, A., Lane, A., Murray, L., Harvey, I., Nair, P., Donovan, J., et al. (2003). Reduced risk of atopic disorders in adults with Helicobacter pylori infection. Eur. J. Gastroenterol. Hepatol. 15, 637-640. doi: 10.1097/00042737-200306000-00010

McLeish, S., and Turner, S. W. (2007). Gene-environment interactions in asthma, Arch. Dis. Childhood 92, 1032-1035. doi: 10.1136/adc.2006.112185

Mishra, S. (2013). Is Helicobacter pylori good or bad? Eur. J. Clin. Microbiol. Infect. Dis. 32, 301-304. doi: 10.1007/s10096-012-1773-9

Murray, C. S., Tannock, G. W., Simon, M. A., Harmsen, H. J., Welling, G. W., Custovic, A., et al. (2005). Fecal microbiota in sensitized wheezy and nonsensitized non-wheezy children: a nested case-control study. Clin. Exp. Allergy 35, 741-745. doi: 10.1111/j.1365-2222.2005.02259.x

Noverr, M. C., Falkowski, N. R., McDonald, R. A., McKenzie, A. N., and Huffnagle, G. B. (2005). Development of allergic airway disease in mice following antibiotic therapy and fungal microbiota increase: role of host genetics, antigen, and interleukin-13. Infect. Immun. 73, 30-38. doi: 10.1128/IAI.73.1.30-38.2005

Nurgalieva, Z. Z., Malaty, H. M., Graham, D. Y., Almuchambetova, R., Machmudova, A., Kapsultanova, D., et al. (2002). Helicobacter pylori infection in Kazakhstan: effect of water source and household hygiene. Am. J. Trop. Med. Hyg. 67, 201-206. doi: 10.4269/ajtmh.2002.67.201

Oertli, M., Noben, M., Engler, D. B., Semper, R. P., Reuter, S., Maxeiner, J., et al. (2013). Helicobacter pylori gamma-glutamyl transpeptidase and vacuolating cytotoxin promote gastric persistence and immune tolerance. Proc. Natl. Acad. Sci. U.S.A. 110, 3047-3052. doi: 10.1073/pnas.12112 48110

Oertli, M., Sundquist, M., Hitzler, I., Engler, D. B., Arnold, I. C., Reuter, S., et al. (2012). DC-derived IL-18 drives Treg differentiation, murine Helicobacter pylori-specific immune tolerance, and asthma protection. J. Clin. Invest. 122, 1082-1096. doi: 10.1172/JCI61029

Okada, H., Kuhn, C., Feillet, H., and Bach, J. F. (2010). The 'hygiene hypothesis' for autoimmune and allergic diseases: an update. Clin. Exp. Immunol. 160, 1-9. doi: 10.1111/j.1365-2249.2010.04139.x

Quah, B. S., Wan-Pauzi, I., Ariffin, N., and Mazidah, A. R. (2005). Prevalence of asthma, eczema and allergic rhinitis: two surveys, 6 years apart, in Kota Bharu, Malaysia. Respirology 10, 244-249. doi: 10.1111/j.1440-1843.2005.00645.x

Radon, K., Windstetter, D., Eckart, J., Dressel, H., Leitritz, L., Reichert, J., et al. (2004). Farming exposure in childhood, exposure to markers of infections and the development of atopy in rural subjects. Clin. Exp. Allergy 34, 1178-1183. doi: $10.1111 / j .1365-2222.2004 .02005 . x$

Raj, S. M., Choo, K. E., Noorizan, A. M., Lee, Y. Y., and Graham, D. Y. (2009). Evidence against Helicobacter pylori being related to childhood asthma. J. Infect. Dis. 199, 914-915; author reply 915-916. doi: 10.1086/597066

Reibman, J., Marmor, M., Filner, J., Fernandez-Beros, M. E., Rogers, L., Perez-Perez, G. I., et al. (2008). Asthma is inversely associated with Helicobacter pylori status in an urban population. PLOS ONE 3:e4060. doi: 10.1371/journal.pone.0004060

Renz, H., Brandtzaeg, P., and Hornef, M. (2012). The impact of perinatal immune development on mucosal homeostasis and chronic inflammation. Nat. Rev. Immunol. 12, 9-23. doi: 10.1038/nri3112

Riedler, J., Braun-Fahrlander, C., Eder, W., Schreuer, M., Waser, M., Maisch, S., et al. (2001). Exposure to farming in early life and development of asthma and allergy: a cross-sectional survey. Lancet 358, 1129-1133. doi: $10.1016 / \mathrm{S} 0140-6736(01) 06252-3$
Robertson, B. H., and Margolis, H. S. (2002). Primate hepatitis B viruses genetic diversity, geography and evolution. Rev. Med. Virol. 12, 133-141. doi: $10.1002 / \mathrm{rmv} .348$

Sasidharan, S., and Uyub, A. M. (2009). Prevalence of Helicobacter pylori infection among asymptomatic healthy blood donors in Northern Peninsular Malaysia. Trans. R. Soc. Trop. Med. Hyg. 103, 395-398. doi: 10.1016/j.trstmh.2008. 11.021

Sears, M. R. (2014). Trends in the prevalence of asthma. Chest 145, 219-225. doi: 10.1378/chest.13-2059

Seiskari, T., Kondrashova, A., Viskari, H., Kaila, M., Haapala, A. M., Aittoniemi, J., et al. (2007). Allergic sensitization and microbial load-a comparison between Finland and Russian Karelia. Clin. Exp. Immunol. 148, 47-52. doi: 10.1111/j.1365-2249.2007.03333.x

Shafiee, S., and Topal, E. (2009). When will fossil fuel reserves be diminished? Energy Policy 37, 181-189. doi: 10.1016/j.enpol.2008.08.016

Sheikh, A., and Strachan, D. P. (2004). The hygiene theory: fact or fiction? Curr. Opin. Otolaryngol. Head Neck Surg. 12, 232-236. doi: 10.1097/01.moo.0000122311.13359.30

Shiotani, A., Miyanishi, T., Kamada, T., and Haruma, K. (2008). Helicobacter pylori infection and allergic diseases: epidemiological study in Japanese university students. J. Gastroenterol. Hepatol. 23, E29-E33. doi: 10.1111/j.1440-1746.2007.05107.x

Simpson, C. R., and Sheikh, A. (2010). Trends in the epidemiology of asthma in England: a national study of 333,294 patients. J. R. Soc. Med. 103, 98-106. doi: $10.1258 /$ jrsm.2009.090348

Sommer, F., Faller, G., Konturek, P., Kirchner, T., Hahn, E. G., Zeus, J., et al. (1998). Antrum- and corpus mucosa-infiltrating CD4 $4^{+}$lymphocytes in Helicobacter pylori gastritis display a Th1 phenotype. Infect. Immun. 66, 5543-5546.

Strachan, D. P. (1989). Hay fever, hygiene, and household size. BMJ 299, 1259-1260. doi: 10.1136/bmj.299.6710.1259

Sundaru, H. (2005). Epidemiology of asthma in Indonesia. Acta Med. Indones. 37, $51-54$.

Syam, A. F., Miftahussurur, M., Makmun, D., Nusi, I. A., Zain, L. H., Zulkhairi, et al. (2015). Risk factors and prevalence of helicobacter pylori in five largest islands of Indonesia: a preliminary study. PLOS ONE 10:e140186. doi: 10.1371/journal.pone. 0140186

Taye, B., Enquselassie, F., Tsegaye, A., Medhin, G., Davey, G., and Venn, A. (2015). Is Helicobacter Pylori infection inversely associated with atopy? A systematic review and meta-analysis. Clin. Exp. Allergy 45, 882-890. doi: $10.1111 /$ cea.12404

Tsang, K. W., Lam, W. K., Chan, K. N., Hu, W., Wu, A., Kwok, E., et al. (2000). Helicobacter pylori sero-prevalence in asthma. Respir. Med. 94, 756-759. doi: 10.1053/rmed.2000.0817

Ueda, M., Kikuchi, S., Kasugai, T., Shunichi, T., and Miyake, C. (2003). Helicobacter pylori risk associated with childhood home environment. Cancer Sci. 94, 914-918. doi: 10.1111/j.1349-7006.2003.tb0 1375.x

Uyub, A. M., Raj, S. M., Visvanathan, R., Nazim, M., Aiyar, S., Anuar, A. K., et al. (1994). Helicobacter pylori infection in north-eastern peninsular Malaysia. Evidence for an unusually low prevalence. Scand. J. Gastroenterol. 29, 209-213. doi: $10.3109 / 00365529409090465$

Vercelli, D. (2006). Mechanisms of the hygiene hypothesis-molecular and otherwise. Curr. Opin. Immunol. 18, 733-737. doi: 10.1016/j.coi.2006. 09.002

von Mutius, E. (2007). Allergies, infections and the hygiene hypothesisthe epidemiological evidence. Immunobiology 212, 433-439. doi: 10.1016/j.imbio.2007.03.002

Vyse, A. J., Gay, N. J., Hesketh, L. M., Andrews, N. J., Marshall, B., Thomas, H. I., et al. (2002). The burden of Helicobacter pylori infection in England and Wales. Epidemiol. Infect. 128, 411-417. doi: 10.1017/S0950268802 006970

Wang, Q., Yu, C., and Sun, Y. (2013). The association between asthma and Helicobacter pylori: a meta-analysis. Helicobacter 18, 41-53. doi: 10.1111/hel.12012

Wang, Y., Bi, Y., Zhang, L., and Wang, C. (2012). Is Helicobacter pylori infection associated with asthma risk? A meta-analysis based on 770 cases and 785 controls. Int. J. Med. Sci. 9, 603-610. doi: 10.7150/ijms.4970 
Webber, M. P., Carpiniello, K. E., Oruwariye, T., and Appel, D. K. (2002). Prevalence of asthma and asthma-like symptoms in inner-city elementary schoolchildren. Pediatr. Pulmonol. 34, 105-111. doi: 10.1002/ppul. 10146

Yoon, S. B., Park, J. M., Lim, C. H., Cho, Y. K., and Choi, M. G. (2014), Effect of Helicobacter pylori eradication on metachronous gastric cancer after endoscopic resection of gastric tumors: a meta-analysis. Helicobacter 19, 243-248. doi: 10.1111/hel.12146

Zevit, N., Balicer, R. D., Cohen, H. A., Karsh, D., Niv, Y., and Shamir, R. (2012). Inverse association between Helicobacter pylori and pediatric asthma in a high-prevalence population. Helicobacter 17, 30-35. doi: 10.1111/j.1523-5378.2011.00895.x

Zhou, X., Wu, J., and Zhang, G. (2013). Association between Helicobacter pylori and asthma: a meta-analysis. Eur. J. Gastroenterol. Hepatol. 25, 460-468. doi: 10.1097/MEG.0b013e32835c280a
Conflict of Interest Statement: DG is a paid consultant and has received research funding from RedHill Biopharma regarding novel $H$. pylori therapies and is a consultant to BioGaia regarding use of probiotics for $H$. pylori infections.

The other authors declare that the research was conducted in the absence of any commercial or financial relationships that could be construed as a potential conflict of interest.

Copyright (๑) 2017 Miftahussurur, Nusi, Graham and Yamaoka. This is an openaccess article distributed under the terms of the Creative Commons Attribution License (CC BY). The use, distribution or reproduction in other forums is permitted, provided the original author(s) or licensor are credited and that the original publication in this journal is cited, in accordance with accepted academic practice. No use, distribution or reproduction is permitted which does not comply with these terms. 